\title{
PENGARUH METODE NUMBERED HEAD TOGETHER BERBANTUAN MEDIA AUDIO VISUAL TERHADAP HASIL BELAJAR DALAM MATERI BANGUN RUANG
}

\author{
Vera Riyanti, Merbela Triposa Nope, Lilian Slow \\ Sekolah Tinggi Keguruan dan Ilmu Pendidikan (STKIP) Melawi \\ Email:vera090891@gmail.com
}

\begin{abstract}
Appropriated learning method has an important role in achievement of a good learning outcomes. This study aims to find out the influence of Numbered Head Together learning method assisted by mathematical audio-visual media on learning outcomes in solid figure. This study used an experimental method in the form of One Group Pretest Posttest Design with the initial test and final test. The population of this study was the fifth grade students of Public Elementary School 01 Semanget consisting of 2 classes namely $V$-A and $V$-B. While the sample of this research was the $V$-A class students. Data collection technique used test and documentation. The instrument of this study was the essay test. Based on the result of data analysis, the average of pretest was 46.65 and the posttest average was 70.55 . The result of the paired samples $t$-test calculation in hypothesis testing are $t_{\text {count }}(8.410)>t_{\text {table }}(2,024)$. It can be concluded that $H_{a}$ is accepted, it means that the Numbered Head Together method assisted by audio visual mathematical media has a big influence on learning outcomes in solid figure. The calculation of the effect size using the Cohen formula obtaines of 1.82, this shows that the method of Numbered Head Together has a big influence on learning outcomes in the material of solid figure.
\end{abstract}

Keywords: Numbered Head Together Method, Audio Visual Media

\section{PENDAHULUAN}

Matematika adalah pembelajaran yang erat kaitannya dengan materi dan soal yang melatih keterampilan pemahaman dan keterampilan berhitung. Pada kenyataannya matematika merupakan salah satu mata pelajaran yang dianggap sulit oleh siswa karena pembelajaran yang cenderung hanya berorientasi pada penyelesaian soal-soal yang terdapat pada buku pelajaran. Disinilah guru mempunyai peran penting dalam proses pembelajaran matematika agar dapat menggunakan metode dan media pembelajaran yang tepat sehingga pengetahuan yang disampaikan dapat dikuasai oleh siswa.

Model pembelajaran yang bersifat kreatif dan inovatif dapat dipilih guru agar siswa tidak bosan dalam pembelajaran dan diharapkan dapat mendukung hasil belajar yang baik. Dalam pembelajaran matematika, model pembelajaran kooperatif juga dipandang dapat memberikan pengaruh positif terhadap siswa baik pada kesempatan bersosialisai maupun hasil belajarnya. Salah satu metode pembelajaran kooperatif yang dapat digunakan dalam pembelajaran matematika yaitu metode Numbered Head Together (NHT).
Model pembelajaran Numbered Head Together (NHT) adalah model pembelajaran kooperatif yang mengajak siswa untuk dapat berpikir bersama dalam menyelesaikan masalah matematika sehingga pemahaman siswa terkait materi yang dipelajari dapat diukur. Alasan peneliti menggunakan metode Numbered Head Together karena setiap siswa dapat menyampaikan ide-ide kemudian saling berdiskusi untuk menyelesaikan masalah matematika, siswa yang pandai dalam kelompok dapat membantu siswa yang kurang pandai dalam menyelesaikan masalah matematika.

Untuk mendukung proses pembelajaran matematika, media pembelajaran juga sangat penting digunakan dengan tujuan pengetahuan dapat disampaikan dengan baik dan dapat memotivasi siswa dalam belajar. Agar siswa dapat pengalaman baru dalam proses pembelajaran, media audio visual digunakan dalam proses pembelajaran menggunakan metode Numbered Heads Together. Media audio visual dipilih sebagai salah satu media pembelajaran yang mendukung karena dapat mencakup indera pendengaran dan penglihatan siswa. 
Berdasarkan studi pendahuluan yang dilakukan peneliti di SD Negeri 01 Semanget diketahui bahwa (1) kegiatan pembelajaran yang dilakukan guru masih dominan menggunakan metode ceramah sehingga siswa belum berperan aktif dalam kegiatan pembelajaran. Walaupun ada beberapa metode pembelajaran yang juga sering diterapkan yaitu metode ceramah, tanya jawab, kelompok dan penugasan. Selain itu; (2) matematika merupakan pelajaran yang dianggap sulit oleh siswa; (3) guru belum pernah menggunakan metode Numbered Head Together berbantuan media audio visual dalam materi bangun ruang; (4) dalam pembelajaran matematika yang berhubungan dengan penggunaan rumus siswa sering salah dalam menempatkan angka-angka ke dalam rumus dengan tepat dan (5) hasil belajar matematika siswa sebagian besar masih dibawah KKM dengan nilai KKM yaitu 65 .

Berdasarkan beberapa hal tersebut peneliti melaksanakan penelitian dengan judul Pengaruh Metode Numbered Head Together Berbantuan Media Audio Visual Matematika terhadap Hasil Belajar dalam materi Bangun Ruang di SD Negeri 01 Semanget.

\section{METODE PENELITIAN}

Metode penelitian yang digunakan dalam penelitian ini adalah metode eksperimen dengan desain penelitian yaitu pre-experimental designs dan bentuk yang digunakan yaitu one group pretest-posttest. Pre-Experimental Designs yang merupakan suatu desain penelitian yang belum merupakan eksperimen sungguh-sungguh karena masih terdapat variabel luar yang ikut berpengaruh terhadap terbentuknya variabel dependen (Sugiyono, 2014: 109). Sedangkan One Group Pretest-Posttest Design adalah desain penelitian yang menggunakan pretest sebelum diberi perlakuan dan posttest setelah diberi perlakuan. Bentuk one group Pretest-Posttest Design sebagai berikut:

\section{$\mathbf{O}_{1} \times \mathbf{O}_{2}$}

Keterangan: $\mathrm{O}_{1}=$ Pretest $; \mathrm{X}=$ Perlakuan yang diberikan; $\mathrm{O}_{2}=$ Posttest. Populasi dalam penelitian ini adalah seluruh siswa di SD Negeri 01 Semanget. Sedangkan sampel dalam penelitian ini adalah siswa kelas V-A SD Negeri 01 Semanget dengan siswa perempuan berjumlah 12 orang dan siswa laki-laki berjumlah 8 orang total keseluruhan siswa berjumlah 20 siswa. Adapun teknik pengumpulan data yang digunakan dalam penelitian ini adalah tes dan dokumentasi. Hendriana dan Sumarmo (2014: 50) mengatakan tes adalah alat ukur yang berupa soal-soal yang berkaitan dengan materi pembelajaran siswa. Tes yang digunakan yaitu tes berbentuk soal esai yang diberikan pada saat dilakukan Pretest dan Posttest. Instrumen tes yang di berikan untuk memperoleh informasi terkait hasil belajar siswa. Sugiyono (2015: 273) menyatakan dokumentasi merupakan catatan peristiwa yang sudah berlalu. Dokumentasi yang digunakan dalam penelitian ini berupa foto-foto yang relevan, tes hasil belajar dan surat-surat yang mendukung penelitian ini.

Instrumen yang digunakan dalam penelitian terlebih dahulu di uji cobakan guna memperoleh validitas, reliabilitas, indeks kesukaran dan daya pembeda. Uji coba dilakukan di SD Negeri 12 Entikong dengan alasan karena memiliki akreditasi sekolah yang sama yaitu terakreditasi B. Menurut Anderson (Lestari dan Yudhanegara, 2015: 190) menyatakan sebuah tes dikatakan valid apabila tes tersebut mengukur apa yang hendak di ukur. Dengan kata lain, validitas suatu instrumen merupakan tingkat ketepatan suatu instrumen dalam mengukur apa yang hendak diukur. Validitas dalam penelitian ini meliputi validitas isi dan validitas empris. validitas isi menurut Lestari dan Yudhanegara (2015: 190) adalah ketepatan instrumen tersebut ditinjau dari segi materi yang akan diteliti. Adapun hal-hal yang akan di validasi adalah rencana Pelaksanaan Pembelajaran (RPP), soal Pretest dan Posttest serta media audio visual. Sedangkan validitas empiris menurut Sudjana (Matondang, 2009: 89) adalah validitas berkenaan dengan ketepatan alat penilaian terhadap konsep yang dinilai sehingga betul-betul menilai apa yang seharusnya dinilai. Dalam penelitian ini untuk menghitung nilai validitas digunakan rumus koefisien korelasi Product Moment Pearson sebagai berikut.

$$
\begin{aligned}
& r_{x y}=\frac{N \sum X Y-\left(\sum X\right)\left(\sum Y\right)}{\left.\left.\quad \text { Keterangan: }: \sum_{x y} X\right)^{2}\right]\left[N Y^{2} Y^{2}\right]-\left(\sum Y Y^{2}\right)^{2}} \\
& \text { Kofisien Korelasi antara }
\end{aligned}
$$

skor butir soal (X) dan total skor (Y); $\mathrm{N}=$ Banyak subjek; $\mathrm{X}=$ Skor butir soal; $\mathrm{Y}=$ Total skor. Untuk mengetahui hasil validitas instrumennya digunakan suatu tolak ukur dalam menginterpretasi derajat validitas instrumen berdasarkan kriteria menurut Guilford (Lestari dan Yudhanegara, 2015: 193) sebagai berikut. 
Tabel 1. Kriteria Interpretasi Validitas Instrumen

\begin{tabular}{cc}
\hline Koefisien Korelasi & Interpretasi Validitas \\
\hline $0,90 \leq \mathrm{r}_{\mathrm{xy}} \leq 1,00$ & Sangat Tinggi \\
\hline $0,70 \leq \mathrm{r}_{\mathrm{xy}}<0,90$ & Tinggi \\
\hline $0,40 \leq \mathrm{r}_{\mathrm{xy}}<0,70$ & Sedang \\
\hline $0,20 \leq \mathrm{r}_{\mathrm{xy}}<0,40$ & Rendah \\
\hline $\mathrm{r}_{\mathrm{xy}}<0,20$ & Sangat Rendah \\
\hline
\end{tabular}

Menurut Lestari dan Yudhanegara (2015: 2016) reliabilitas suatu instrumen adalah keajegan atau kekonsistenan instrumen tersebut diberikan pada subjek yang sama meskipun oleh orang yang berbeda, waktu yang berbeda atau tempat yang berbeda, maka akan memberikan hasil yang sama atau relative sama (tidak berbeda secara signifikan). Dalam penelitian ini peneliti menggunakan rumus Alpha Cronbach sebagai berikut.

$$
\left.\mathrm{r}=\underset{n-1}{\left(\frac{n}{n}\right.}\right)\left(1-\underline{\Sigma}_{S_{t}^{2}}^{\underline{\underline{2}}^{2}}\right)
$$

Keterangan: $\mathrm{r}=$ Koefisien reliabilitas; $\mathrm{n}=$ Banyaknya butir soal; $S_{i}^{2}=$ Variansi skor butir soal ke-i; $S_{t}^{2}=$ Variansi skor total. Penentuan kategori dari reliabilitas instrumen mengacu pada pengklasifikasian reliabilitas instrumen menurut Guilford (Lestari dan Yudhanegara, 2015: 206) sebagai berikut.

Tabel 2. Kriteria Interpretasi Reliabilitas Instrumen

\begin{tabular}{lc}
\hline Koefisien Korelasi & Interpretasi Reliabilitas \\
\hline $0,81<\mathrm{r} \leq 1,00$ & Sangat Tinggi \\
\hline $0,61<\mathrm{r}<0,8$ & Tinggi \\
\hline $0,41<\mathrm{r}<0,6$ & Cukup \\
\hline $0,21<\mathrm{r}<0,4$ & Rendah \\
\hline $0,00<\mathrm{r}<0,2$ & Sangat Rendah \\
\hline
\end{tabular}

Indeks kesukaran dilakukan untuk mengetahui tingkat mudah atau sulitnya butir soal yang akan digunakan dalam penelitian. Indeks ini biasa dinyatakan dengan proporsi yang besarnya antara 0,00 sampai 1,00 . Semakin besar indeks kesukaran berarti soal tersebut semakin mudah. Untuk menghitung indeks kesukaran soal uraian dapat digunakan rumus dibawah ini menurut Lestari dan Yudhanegara (2015: 224) sebagai berikut.

$\mathrm{IK}=\frac{X}{S} M I$

Keterangan: IK $=$ Indeks kesukaran butir soal; $X=$ Rata-rata skor jawaban siswa pada suatu butir soal
SMI = Skor maksimum ideal; Kriteria untuk menafsirkan indeks kesukaran menurut Lestari dan Yudha Negara (2015: 224) sebagai berikut.

Tabel 3. Kriteria Interpretasi Indeks Kesukaran Instrumen IK Interpretasi Indeks Kesukaran

\begin{tabular}{rc}
\hline $\mathrm{IK}=0,00$ & Terlalu sukar \\
\hline $0,00<\mathrm{IK} \leq 0,30$ & Sukar \\
\hline $0,30<\mathrm{IK} \leq 0,70$ & Sedang \\
\hline $0,70<\mathrm{IK}<1,00$ & Mudah \\
\hline $\mathrm{IK}=1,00$ & Terlalu mudah \\
\hline
\end{tabular}

Daya pembeda soal adalah suatu kemampuan soal dapat membedakan siswa yang berkemampuan tinggi dan siswa yang berkemampuan rendah. Untuk menghitung daya pembeda instrumen tes uraian dapat menggunakan rumus sebagai berikut.

$\mathrm{DB}=J_{A}$

Keterangan: $\mathrm{S}_{\mathrm{A}}=$ Jumlah skor kelompok atas suatu butir; $\mathrm{S}_{\mathrm{B}}=$ Jumlah skor kelompok bawah suatu butir; $\mathrm{J}_{\mathrm{A}}=$ Jumlah skor ideal suatu butir; Analisis data dilakukan sebagai cara untuk mengolah data menjadi informasi agar data yang sudah didapatkan mudah dipahami dan bermanfaat untuk solusi permasalahan dalam penelitian. Analisis data yang dilakukan dalam penelitian ini yaitu sebagai berikut: (1) Untuk menganalisis hasil tes digunakan rumus mean untuk mencari rata-rata; (2) Uji normalitas adalah sebuah uji statistik yang dilakukan dengan tujuan untuk menilai sebaran data pada sebuah kelompok data atau variabel, apakah sebaran data tersebut berdistribusi normal atau tidak. Perhitungan uji normalitas yang digunakan yaitu uji chi kuadrat; (3) Berdasarkan hasil uji normalitas, jika data berdistribusi normal dilakukan uji t dua sampel dan jika data berdistribusi tidak normal maka digunakan statistik non parametrik dengan uji Wilcoxon untu menjawab hipotesis penelitian; (4) Untuk menganalisis besar pengaruh pembelajaran menggunakan metode Numbered Head together berbantuan media audio visual terhadap hasil belajar siswa dilakukan perhitungan Effect Size. Sebagaimana yang dikemukakan oleh Salkind (Nur'asiah, 2016: 37), "Effect size is a term used to describe the magnitude of a treatment effect". Rumus untuk menghitung effect size jika korelasinya kecil menurut Cohen (Utari dan Fatmawati 2015) sebagai berikut.

$$
\mathrm{d}=\frac{M_{i}-M_{B}}{\sqrt{S_{B}^{2}+S D^{2}}}
$$


Keterangan: $\mathrm{d}=$ Effect size; $\mathrm{M}_{\mathrm{i}}=$ Mean posttest $; \mathrm{M}_{\mathrm{B}}=$ Mean pretest $; \mathrm{SD}_{\mathrm{B}}=$ Standar deviasi pretest $; \mathrm{SD}_{\mathrm{i}}=$ Standar deviasi posttest; Sedangkan rumus effect size jika korelasinya besar menurut Cohen (Fatmawati dan uteri, 2015) adalah sebagai berikut.

Tabel 4. Kriteria Effect size

\begin{tabular}{cc}
\hline Nilai Effect size & Kriteria \\
\hline $\mathrm{d}<0,1$ & Tidak berpengaruh \\
\hline $0,1 \leq \mathrm{d} \leq 0,4$ & Kecil \\
\hline $0,4 \leq \mathrm{d} \leq 0,8$ & Sedang \\
\hline$>0,80$ & Besar \\
\hline
\end{tabular}

$\mathrm{d}=\mathrm{t} \sqrt{\frac{2(1-r)}{N}}$

Keterangan: $\mathrm{d}=$ Effect size; $\mathrm{r}=$ Korelasi; $\mathrm{t}=$ Nilai uji t; $\mathrm{N}=$ Jumlah partisipan. Adapun kriteria hasil perhitungan effect size sebagai berikut.

\section{HASIL PENELITIAN DAN PEMBAHASAN Hasil Penelitian}

Instrumen yang digunakan dalam penelitian ini terlebih dahulu di uji kualitasnya melalui uji validitas, reliabilitas, indeks kesukaran dan daya pembeda. Hasil perhitungan uji validitas, reliabilitas indeks kesukaran dan daya pembeda dapat dilihat pada tabel di bawah ini.

Tabel 5. Rekapitulasi Hasil Uji Validitas, Reliabilitas, Indeks Kesukaran dan Daya Pembeda Soal

\begin{tabular}{|c|c|c|c|c|c|c|c|c|}
\hline $\begin{array}{l}\text { No. } \\
\text { Soal }\end{array}$ & Nilai & $\begin{array}{c}\text { Tingkat } \\
\text { Validitas }\end{array}$ & $\begin{array}{c}\text { Varians } \\
\text { Soal }\end{array}$ & $\begin{array}{c}\text { Tingkat } \\
\text { Reliabilitas }\end{array}$ & Nilai & $\begin{array}{c}\text { Tingkat } \\
\text { Kesukaran }\end{array}$ & Nilai & $\begin{array}{c}\text { Daya } \\
\text { Pembeda }\end{array}$ \\
\hline 1 & 0,89 & $\mathrm{~T}$ & 6,4058 & \multirow{8}{*}{$\begin{array}{c}\text { Reliabilitas } \\
=0,95 \\
\text { (Sangat } \\
\text { Tinggi) }\end{array}$} & 0,76 & Mudah & 0,30 & Cukup \\
\hline 2 & 0,91 & ST & 11,19 & & 0,66 & Sedang & 0,40 & Baik \\
\hline 3 & 0,88 & $\mathrm{~T}$ & 5,16 & & 0,74 & Mudah & 0,27 & Cukup \\
\hline 4 & 0,87 & $\mathrm{~T}$ & 6,06 & & 0,72 & Mudah & 0,31 & Cukup \\
\hline 5 & 0,84 & $\mathrm{~T}$ & 9,91 & & 0,59 & Sedang & 0,41 & Baik \\
\hline 6 & 0,84 & $\mathrm{~T}$ & 6,50 & & 0,61 & Sedang & 0,30 & Cukup \\
\hline 7 & 0,92 & ST & 10,30 & & 0,65 & Sedang & 0,43 & Baik \\
\hline 8 & 0,81 & $\mathrm{~T}$ & 5,13 & & 0,68 & Sedang & 0,31 & Cukup \\
\hline
\end{tabular}

Berdasarkan tabel 5 diatas, dari 8 butir soal yang di uji cobakan dapat disimpulkan bahwa 8 butir soal tersebut layak digunakan dalam penelitian. Penelitian ini dilakukan untuk mengetahui seberapa besar pengaruh metode Numbered Head Together berbantuan media audio visual matematika terhadap hasil belajar dalam materi bangun ruang di SDN 01 Semanget.
Jumlah sampel dalam penelitian ini yaitu 20 siswa yang terdiri dari 12 siswa perempuan dan 8 siswa laki-laki. Dari sampel tersebut diperoleh data hasil pretest dan posttest. Data pretest didapatkan dari hasil belajar sebelum diberikan perlakuan sedangkan data posttest didapatkan dari hasil belajar setelah diberikan perlakuan. Berikut ini rekapitulasi hasil belajar pretest dan posttest

Tabel 6. Hasil Pretest dan Posttest Siswa

\begin{tabular}{cccc}
\hline No & Kode Siswa & Nilai Pretest & Nilai Posttest \\
\hline 1 & AR & 53 & 80 \\
\hline 2 & AY & 43 & 67 \\
\hline 3 & ATPDM & 61 & 89 \\
\hline 4 & CAH & 35 & 69 \\
\hline 5 & CF & 54 & 65 \\
\hline 6 & FR & 53 & 67 \\
\hline 7 & GPR & 63 & 71 \\
\hline 8 & HN & 46 & 49 \\
\hline 9 & KK & 59 & 71 \\
\hline 10 & MDW & 47 & 89 \\
\hline 11 & M & 47 & 60 \\
\hline
\end{tabular}




\begin{tabular}{lccc}
\hline 12 & NS & 52 & 93 \\
\hline 13 & $\mathrm{RS}$ & 15 & 35 \\
\hline 14 & $\mathrm{RA}$ & 57 & 79 \\
\hline 15 & $\mathrm{SPK}$ & 36 & 82 \\
\hline 16 & $\mathrm{SN}$ & 47 & 78 \\
\hline 17 & $\mathrm{~T}$ & 60 & 75 \\
\hline 18 & $\mathrm{VJJ}$ & 22 & 65 \\
\hline 19 & $\mathrm{XN}$ & 42 & 57 \\
\hline 20 & $\mathrm{RC}$ & 41 & 70 \\
\hline \multicolumn{7}{c}{ Standar Deviasi } & $\mathbf{4 6 , 6 5}$ & $\mathbf{7 0 , 5 5}$ \\
\hline & Min & $\mathbf{1 2 , 5 7}$ & $\mathbf{1 3 , 8 9}$ \\
\hline & $\mathbf{1 5}$ & $\mathbf{6 3}$ & $\mathbf{3 5}$ \\
\hline
\end{tabular}

Berdasarkan data tabel tersebut maka dapat diketahui bahwa terdapat perbedaan hasil belajar pretest dan posttest. Dilihat dari rata-rata kelas hasil belajar pretest adalah 46,65 sedangkan ratarata kelas hasil belajar posttest adalah 70,55. Data hasil belajar pretest dan posttest dapat dilihat pada grafik di bawah ini

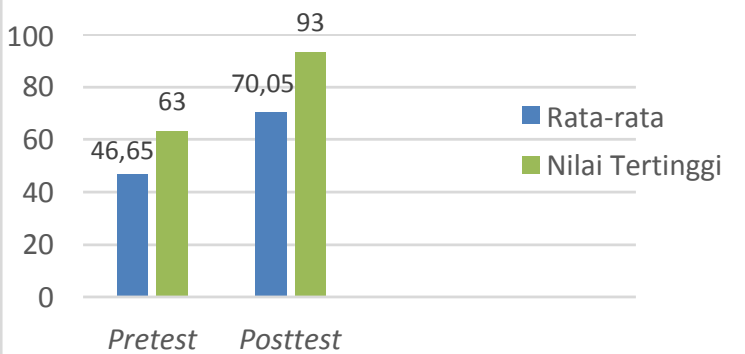

Grafik 1. Grafik Hasil Belajar Pretest dan Posttes

Berdasarkan hasil perhitungan uji normalitas data pretest diperoleh $\mathrm{X}^{2}{ }_{\text {hitung }}<\mathrm{X}^{2}$ tabel yaitu 4,108 $<9,488$ artinya data berdistribusi normal. Sedangkan hasil perhitungan uji normalitas posttest diperoleh $\mathrm{X}^{2}$ hitung $<\mathrm{X}_{\text {tabyyaitu }}^{2} 4,841<$ 9,488 artinya data berdistribusi normal. Dari hasil perhitungan kedua data diatas maka dapat disimpulkan bahwa data tersebut berdistribusi normal dan dapat dilanjutkan perhitungan uji hipotesis menggunakan uji $\mathrm{t}$ paired samples. Pengujian hipotesis dalam penelitian ini menggunakan hipotesis alternatif $\left(\mathrm{H}_{\mathrm{a}}\right)$ dan hipotesis nol $\left(\mathrm{H}_{0}\right)$. Hipotesis alternatif merupakan wujud dari hipotesis penelitian berupa pernyataan dan perlu dibuktikan kebenarannya. Sementara hipotesis nol atau nihil merupakan tandingan dari hipotesis alternatif yaitu berupa pernyataan yang berlawanan dengan hipotesis alternatif.

\section{Pembahasan}

Penelitian ini dilakukan untuk mengetahui seberapa besar pengaruh metode Numbered Head Together berbantuan media audio visual matematika terhadap hasil belajar dalam materi bangun ruang untuk sub materi volume bangun ruang kubus dan balok. Berdasarkan penelitian yang dilakukan pada SDN 01 Semanget, pembelajaran menggunakan metode Numbered Head Together berbantuan media audio visual matematika berdampak positif terhadap hasil belajar siswa. Dalam proses pembelajaran dengan menggunakan metode Numbered Head Together berbantuan media audio visual, setiap siswa saling bekerja sama dalam kelompoknya. Siswa kelas VA di SDN 01 Semanget sangat merasa senang dengan pembelajaran berkelompok dan antusias mereka untuk belajar semakin terlihat ketika penjelasan materi disampaikan dengan menggunakan media audio visual yang dapat mereka lihat dan dengar. Sebelum kelompok dibentuk, peneliti menjelaskan bagaimana tahapan pembelajaran dengan metode Numbered Head Together karena siswa belum pernah mendengar dan mengikuti pembelajaran dengan metode Numbered Head Together. Setelah penjelasan materi disampaikan, tugas kelompok diberikan dengan siswa dibagi menjadi 4 kelompok yang setiap kelompoknya terdiri dari siswa laki-laki dan perempuan yang berjumlah 5 siswa. Setiap siswa dalam kelompoknya mendapatkan nomor yang berbeda dan nomor tersebut diletakkan di atas kepala karena nomor yang telah disiapkan peneliti dibuat seperti mahkota. Ketika sudah berada di kelompoknya masing-masing siswa diberikan tugas kelompok berupa 5 soal esai dan siswa diberikan waktu untuk saling bekerja sama.

Pembelajaran berlanjut dengan peneliti menyebutkan satu nomor pada setiap kelompok 
dan nomor yang disebutkan namanya maju ke depan kelas untuk mempresentasikan hasil diskusi kelompoknya dan ditulis dipapan tulis. Setelah itu peneliti meminta siswa dari kelompok lain untuk memberikan pertanyaan kepada siswa yang presentasi. Setelah kegiatan pemangggilan nomor dilakukan, peneliti meminta siswa untuk mengumpulkan tugas kelompoknya dan pada akhir pembelajaran peneliti bersama siswa membuat evaluasi hasil pembelajaran serta membagikan hadiah kepada setiap kelompok karena dapat saling bekerja sama dengan baik dalam diskusi kelompok masing-masing.

Secara umum penelitian ini bertujuan untuk mengetahui rata-rata kelas hasil belajar siswa sebelum dan sesudah mendapatkan pembelajaran dengan metode Numbered Head Together berbantuan media audio visual terhadap hasil belajar siswa pada sub materi volume kubus dan balok. Serta untuk mengetahui seberapa besar pengaruh pembelajaran menggunakan metode ini. Berdasarkan hasil penelitian terdapat perbedaan rata-rata kelas hasil belajar sebelum diberikan perlakuan (pretest) dan setelah diberikan perlakuan (posttest). Rata-rata kelas hasil belajar pretest diketahui lebih rendah daripada rata-rata kelas hasil belajar posttest yaitu nilai rata-rata kelas pretest yaitu 46,65 dan masih dibawah KKM 65. Sedangkan nilai rata-rata kelas posttest yaitu 70,55 sudah di atas KKM 65.

Dapat terlihat peningkatan hasil berdasarkan dari nilai hasil belajar posttest yang diberikan yaitu dari 20 siswa yang mendapatkan perlakuan 16 siswa mendapatkan nilai tuntas dengan perolehan nilai lebih besar atau sama dengan 65 . Setelah data pretest dan posttest diolah didapatkan hasil belajar mendapatkan persentase ketuntasan $80 \%$ dan hanya $20 \%$ siswa yang tidak tuntas. Sedangkan hasil belajar pretest persentase ketuntasannya $0 \%$ ini berarti seluruh siswa mendapatkan nilai $100 \%$ tidak tuntas.

Hasil uji hipotesis menunjukkan pembelajaran dengan menggunakan metode Numbered Head Together berbantuan media audio visual matematika berpengaruh signifikan terhadap hasil belajar dalam materi bangun ruang di SD Negeri 01 Semanget. Hal ini didapatkan dari hasil perhitungan hipotesis menggunkan uji $\mathrm{t}$ paired samples terdapat perbedaan $t_{\text {hitung }}$ dengan $\mathrm{t}_{\text {tabel }}$ yaitu $\mathrm{t}_{\text {hitung }}>\mathrm{t}_{\text {tabel }}$ atau $8,410>2,024$. Kemudian untuk mengetahui seberapa besar pengaruhnya berdasarkan pada nilai effect size Cohen yakni sebesar 1,82, melihat nilai tersebut maka hal ini termasuk dalam kategori besar karena $1,82>0,80$. Dengan demikian pembelajaran dengan menggunakan metode Numbered Head Together berbantuan media audio visual matematika berpengaruh besar terhadap hasil belajar dalam materi bangun ruang di SD Negeri 01 Semanget.

\section{SIMPULAN DAN SARAN Simpulan}

Berdasarkan analisis data, hasil penelitian dan pembahasan yang telah dilakukan maka dapat disimpulkan bahwa rata-rata hasil belajar siswa sebelum diberikan perlakuan dengan data yang didapatkan dari pretest mempunyai nilai rata-rata kelas 46,65 masih dibawah KKM yang sudah ditentukan sekolah yaitu 65 dengan persentase ketuntasan $0 \%$ dari 20 siswa, skor minimal 15, skor maksimal 63, dan standar deviasi 12,57. Sedangkan rata-rata kelas hasil belajar siswa setelah diberikan perlakuan dengan data yang didapatkan dari posttest mempunyai nilai rata-rata kelas 70,55 sudah di atas KKM yang ditentukan sekolah yaitu 65 dengan persentase ketuntasan $80 \%$ dari 20 siswa, skor minimal 35, skor

maksimal 93, dan standar deviasi 13,89. Dikarenakan siswa mendapatkan metode pembelajaran yang belum pernah siswa dapatkan dan didukung oleh penggunaan media audio visual.

Pembelajaran metode Numbered Head Together berbantuan media audio visual matematika berpengaruh signifikan terhadap hasil belajar dalam materi bangun ruang di SD Negeri 01 Semanget. Hal ini didasarkan pada hasil perhitungan analisis uji t pairedsamples terdapat perbedaan nilai $t_{\text {hitung }}$ dengan $t_{\text {tabel, }}$ yaitu $8,501>$ 2,024 . Berdasarkan hasil perhitungan effect size uji t dengan menggunakan rumus perhitungan Cohen, diperoleh nilai effect size 1,82 diinterpretasikan ke dalam tingkatan pengaruh yang besar. Sehingga dapat disimpulkan bahwa pembelajaran dengan menggunakan metode Numbered Head Together berbantuan media audio visual matematika memberikan pengaruh yang besar terhadap hasil belajar dalam materi bangun ruang di SD Negeri 01 Semanget.

\section{Saran}

Berdasarkan kesimpulan hasil dari penelitian yang telah dilakukan, beberapa saran yang peneliti dapat sampaikan antara lain: (1) diharapkan kepada guru untuk menggunakan beberapa variasi metode dan media yang sesuai dalam proses pembelajaran yang dapat meningkatkan gairah belajar siswa, salah satunya menggunakan metode Numbered Head Together dengan bantuan media 
audio visual; (2) untuk peneliti selanjutnya, agar dapat melakukan penelitian lanjutan dengan menggunakan metode dan media yang sesuai dan (3) untuk guru dan dosen senantiasa terus mengembangkan pengetahuan dan kemampuan melalui inovasi berbasis literasi dalam mengembangkan konsep, model, metode dan strategi dalam pembelajaran

\section{DAFTAR PUSTAKA}

Lestari, Karunia Eka dan Yudhanegara, Mokhammad Ridwan. 2015. Penelitian Pendidikan Matematika. Bandung: PT Refika Aditama.

Matondang, Zulkifli. 2009. Validitas dan Reliablitias Suatu Instrumen Penelitian. Jurnal Tabularasa PPS UNIMED. Vol. 6 No. 1: $\quad 89 \quad$ (online) tersedia: http://digilib.unimed.ac.id/705/1/Validitas\%2 0dan\%20reliabilitas\%20suatu\%20instrumen \%20penelitian.pdf. (tanggal buka 30 November 2018).
Nur'asiah, Risma Farissa. 2016. Peningkatan Kemampuan Berpikir Kritis dan Profil Keeterampilan Berkomunikasi Siswa SMP melalui Penggunaan Multimedia Based Integrated instruction (Mbi2) pada Pembelajaran Alat Optik. Universitas Pendidikan Indonesia.

Sugiyono. 2014. Metode Penelitian Pendidikan Pendekatan Kuantitatif, Kualitatif, dan R\&D. Bandung: Alfabeta. . 2015. Metode Penelitian Tindakan Komprehensif. Bandung: Alfabeta.

Utari dan Fatmawati. 2015. Penerapan Levels of Inquiry untuk Meningkatkan Literasi Sains Siswa SMP Tema Limbah dan Upaya Penanggulangannya. EDUSAINS. Vol 7 No 2:155(online) http://journal.iunjkt.ac.id/ tersedia: index.php/edusains. (tanggal buka $1 \mathrm{Mei}$ 2019). 